\title{
Open-globe injuries in Palestine: epidemiology and factors associated with profound visual loss at St. John Eye Hospital, Jerusalem
}

\author{
Riyad Banayot $\odot$
}

St. John Eye Hospital, Jerusalem, Palestine

\begin{abstract}
BACKGROUND: The purpose was to describe the epidemiology of open-globe injury (OGI) in Palestine and identify the prognostic factors associated with profound visual loss.

MATERIAL AND METHODS: The current study is a retrospective review of hospital files for 83 consecutive patients with OGI who presented to St. John Eye Hospital, Jerusalem, within 5 years, between 2009 and 2013. Demographic details included age, gender, wound characteristics, and visual acuity (VA). The Ocular Trauma Classification Group was used for wound location, classification, and scoring for each case.

RESULTS: We identified 83 OGI that presented to St. John eye hospital. The study group included 62 males and 21 females. The mean age was 16.66 years \pm 3.216 . The most frequent injuries were playground injuries $(59 \%)$, followed by workplace injuries (26.5\%). Penetrating injuries represented $45.8 \%$ of injuries, and rupture globes occurred in 39.8\% of cases. The most frequent objects causing injury were metal (31.3\%) and stone (20.5\%). Kinetic impact projectiles were a statistically significant poor prognostic factor for the visual outcome. Variables that were statistically significant poor prognostic factors for visual outcome included: retinal detachment, macular scar, vitreous hemorrhage.

CONCLUSION: This study showed that the act of demonstration, street injuries, kinetic impact projectiles, zone III injuries, globe disruption, retinal detachment, vitreous hemorrhage, and a poor VA at the first visit are poor prognostic factors for OGI. Recognition of these prognostic factors will help the ophthalmologist evaluate the injury and its prognosis.
\end{abstract}

KEY WORDS: open-globe injury; visual outcome; prognostic factors; epidemiology; Palestine

Ophthalmol J 2021; Vol. 6, 165-170

\section{INTRODUCTION}

Open-globe injury (OGI) represents a cause of significant visual impairment and causes profound emotional trauma to patients and their fami- lies. These injuries impose high costs on individuals, families, and the health system. Open-globe injury treatment is time-consuming, costly, and often leads to loss of productivity in these individuals. 
In 1997, the Ocular Trauma Classification Group convened and developed the Birmingham Eye Trauma Terminology System (BETTS) [1], which defined OGI as a traumatic, full-thickness wound of the globe. The definition also includes penetrated, perforated, and ruptured globes along with intraocular foreign bodies. Next, the group developed the Ocular Trauma Score (OTS) [2], which is used to predict the visual outcome of patients after open-globe ocular trauma.

Worldwide, approximately 200,000 people suffer from OGI, with an annual global incidence rate of 3.5/100,000 persons [3].

Limited information is available in Palestine regarding the epidemiology of OGI. This study reviewed the clinical features, outcomes, and visual prognosis of OGI in patients presenting to St. John Eye Hospital in Jerusalem over 5 years. The purpose of this study was to describe the epidemiology of OGI in Palestine and to identify the prognostic factors associated with profound visual loss. The results can play an important role in developing effective medical services and preventive strategies for a population.

\section{MATERIAL AND METHODS}

The current study is a retrospective review of hospital files for 83 consecutive patients with open OGI, who presented to St. John Eye Hospital, Jerusalem, within 5 years, between 2009 and 2013. We undertook the review 5-years after the study period. This review follows a previous study by the author, where ocular trauma represented the fifth most common disorder seen with a mean of $7 \%$ [4].

We reviewed patients' medical records and excluded patients whose visual outcome data were missing from the files. Our review's demographic data included age, gender, wound characteristics presenting, and final visual acuity (VA), and concomitant ocular damage.

The Birmingham Eye Trauma Terminology (BETT) [1] used the following classifications of wounds:

- an open globe injury - a full-thickness wound of the eyewall (cornea and/or sclera);

- a ruptured wound - a full-thickness wound of the eyewall caused by a blunt object,

- penetrating wound - a single laceration of the eyewall caused by a sharp object;

- wound with intraocular foreign body (IOFB).
The Ocular Trauma Classification Group [2] used the following classifications for wound locations:

- zone I for injury to the cornea and limbus;

- zone II injury involved the anterior $5 \mathrm{~mm}$ from the limbus;

- zone III injury extended to the posterior by more than $5 \mathrm{~mm}$ from the limbus.

We calculated the ocular trauma score (OTS) for each case from existing data. All trauma patients suspected of an IOFB had computed tomography done.

We divided the presenting and final VA into the following categories: $6 / 6$ to $6 / 12,6 / 15$ to $6 / 60$, counting fingers (CF) to $5 / 60$, hand movement (HM) to light perception (LP), and no light perception (NLP).

Ethical approval and permission to conduct the study were obtained from St. John Eye hospital Ethics committee. We concealed the names of patients on archived medical records to maintain the confidentiality of the study.

We analyzed stored data using Wizard Data Analysis version 1.9.48 (Evan Miller, Chicago, Illinois, USA). We evaluated the collected data for the effects of prognostic factors on profound visual loss, which was defined as VA of CF to no light perception (NLP). For the statistical tests, we used a p-value $<0.05$ to be statistically significant. We are reporting descriptive statistics on patient demographics and clinical features.

\section{RESULTS}

We identified 83 open globe injuries that presented to St. John eye hospital. Table 1 illustrates the characteristics of open globe injuries.

The mean age was 16.66 years \pm 3.216 (range from 1 to 58 years). Patients in the age group (0-9) years old represented $47 \%$ of cases. Children below the age of 19 represented $65.1 \%$ of cases, making them vulnerable to OGI compared to other age groups. The study group included $62(74.7 \%)$ males and $21(25.3 \%)$ females, with a ratio of nearly 3:1. This disparity signifies the rule of gender susceptibility to OGIs and higher risk exposure of males.

There were no bilateral OGIs in our study group. Injuries occurred in $37(44.6 \%)$ right eyes and $46(55.4 \%)$ left eyes.

Statistically significant poor prognostic factors for the visual outcome included: playground and 


\begin{tabular}{|c|c|c|}
\hline Variables & $\begin{array}{c}\text { No. } \\
(T=83)\end{array}$ & $\%$ \\
\hline \multicolumn{3}{|l|}{ Place of injury } \\
\hline Playground & 49 & 59 \\
\hline Work & 22 & 26.5 \\
\hline Street & 11 & 13.3 \\
\hline Home & 1 & 1.2 \\
\hline \multicolumn{3}{|l|}{ Activity } \\
\hline Playing & 47 & 56.6 \\
\hline Accident & 16 & 0.3 \\
\hline Demonstration & 9 & 10.8 \\
\hline Hammering & 7 & 8.4 \\
\hline Fight & 3 & 3.6 \\
\hline Mowing & 1 & 1.2 \\
\hline \multicolumn{3}{|l|}{ Object } \\
\hline Metal & 26 & 31.3 \\
\hline Stone & 17 & 20.5 \\
\hline Kinetic impact projectile & 9 & 10.8 \\
\hline Glass & 7 & 8.4 \\
\hline Wood & 7 & 8.4 \\
\hline Fist & 4 & 4.8 \\
\hline Tree branch & 3 & 3.6 \\
\hline Miscellaneous & 10 & 12 \\
\hline \multicolumn{3}{|l|}{ BETT type } \\
\hline Penetration & 38 & 45.8 \\
\hline Rupture & 33 & 39.8 \\
\hline Penetration + IOFB & 6 & 7.2 \\
\hline Unknown & 6 & 7.2 \\
\hline \multicolumn{3}{|l|}{ BETT zone } \\
\hline I & 54 & 65.1 \\
\hline II & 20 & 24.1 \\
\hline III & 9 & 10.8 \\
\hline \multicolumn{3}{|l|}{ OTS score } \\
\hline $1(0-44)$ & 10 & 12 \\
\hline $2(45-65)$ & 26 & 31.3 \\
\hline $3(66-80)$ & 37 & 44.6 \\
\hline $4(81-91)$ & 10 & 12 \\
\hline
\end{tabular}

BETT — Birmingham eye trauma terminology; IOFB — intra-ocular foreign body; OTS - ocular trauma score

street injuries, kinetic impact projectiles, zone I and zone III injuries, OTS 1 and OTS 3, globe disruption, iris prolapse, retinal detachment, macular scar, vitreous hemorrhage, phthisis, enucleation/evisceration, presenting visual acuity categories (NLP) and $(6 / 15$ to $6 / 60)$. Table 2 illustrates the final visual outcomes and prognostic factors.

\section{Place of injury and activity}

Playground injuries (59\%) were the most frequent place of injury, which was followed by workplace injuries $(26.5 \%)$. The most frequently reported activity during these injuries was playing (56.6\%).

\section{Offending object, BEET type, zone, and OTS score}

Penetrating injuries represented $45.8 \%$ of injuries, and rupture globes occurred in $39.8 \%$ of cases. The most frequent objects causing injury were metal $(31.3 \%)$ and stone $(20.5 \%)$. Of all injuries zone I constituted $65.15 \%$, and zone II constituted $24.1 \%$ of cases. Ocular trauma score $3(44.6 \%)$ and OTS $2(31.3 \%)$ were the most common scores seen.

\section{Concomitant ocular damage}

Iris prolapse was the most common concomitant ocular damage found in our study at a frequency of $28.9 \%$. Other problems included cataract (19.3\%), vitreous loss $(19.3 \%)$, hyphema (10.8\%), globe disruption $(8.4 \%)$, uveal prolapse $(4.8 \%)$ and hypopyon $(2.4 \%)$. There was no concomitant ocular damage in $6 \%$ of cases.

\section{Late complications}

Only one case developed sympathetic ophthalmia, and another case developed endophthalmitis.

\section{Presenting visual acuity}

The presenting VA worse than $6 / 60$ constituted most cases $(80.7 \%)$; only $19.3 \%$ of patients had a presenting VA better than $6 / 60$. However, the final VA improved with more than doubling the number of cases $(51.8 \%)$, with VA better than $6 / 60$.

\section{DISCUSSION}

This study is a retrospective assessment of the medical records of OGI patients admitted to St. John Eye Hospital in Jerusalem, Palestine. The study evaluates the prognostic factors responsible for the final visual outcomes after OGI in Palestinian patients. This is the first study that examines the prognostic factors of OGI in the Palestinian population to the best of our knowledge.

In accordance with previous studies, OGI are more common in the younger population (age group $0-9$ years old) and occur mainly among males $(74.7 \%)$ of patients. The male predominance (male: female ratio of nearly 3:1) observed in our current study was exhibited in several studies $[6,10,11]$. 


\begin{tabular}{|c|c|c|c|c|c|}
\hline Category (No.) & $6 /--6 / 12$ & $6 / 15-6 / 60$ & $\begin{array}{l}\text { Profound } \\
\text { visual loss }\end{array}$ & Total & $\mathrm{p}$-value \\
\hline \multicolumn{5}{|l|}{ Age } & 0.425 \\
\hline \multicolumn{5}{|l|}{ Sex } & 0.05 \\
\hline \multicolumn{5}{|l|}{ Affected eye } & 0.941 \\
\hline \multicolumn{5}{|l|}{ Time delay } & 0.143 \\
\hline \multicolumn{5}{|l|}{ Activity } & 0.032 \\
\hline Demonstration & 1 & 0 & 8 & 9 & $0.009 *$ \\
\hline \multicolumn{5}{|l|}{ Place of injury } & 0.012 \\
\hline Playground & 20 & 11 & 18 & 49 & $0.04^{* *}$ \\
\hline Street & 1 & 0 & 10 & 11 & $0.002^{*}$ \\
\hline \multicolumn{5}{|l|}{ Object } & 0.086 \\
\hline Kinetic impact projectiles & 1 & 0 & 8 & 9 & $0.009 *$ \\
\hline Miscellaneous & 3 & 1 & 0 & 4 & $0.049 * *$ \\
\hline \multicolumn{5}{|l|}{ BETT type } & 0,094 \\
\hline \multicolumn{5}{|l|}{ BETT zone } & 0,016 \\
\hline Zone I & 20 & 14 & 20 & 54 & $0.02^{* *}$ \\
\hline Zone III & 1 & 0 & 8 & 9 & $0.009 *$ \\
\hline Concomitant problems & & & & & 0.011 \\
\hline Iris prolapse & 11 & 7 & 6 & 24 & $0.027^{* *}$ \\
\hline Globe disruption & 0 & 0 & 7 & 7 & $0.004^{*}$ \\
\hline Causes of decreased vision & & & & & $<0.001$ \\
\hline $\mathrm{RD}$, macular scar, vitreous hemorrhage & 0 & 0 & 4 & 4 & $0.034^{*}$ \\
\hline Phthisis & 0 & 0 & 5 & 5 & $0.017^{*}$ \\
\hline Enucleation/Evisceration & 0 & 0 & 7 & 7 & $0.004^{*}$ \\
\hline Good visual acuity & 26 & 0 & 0 & 26 & $<0.001^{* *}$ \\
\hline \multicolumn{5}{|l|}{ Late complications } & 0.09 \\
\hline Retinal detachment & 1 & 1 & 9 & 11 & $0.016 *$ \\
\hline \multicolumn{5}{|l|}{ Presenting visual acuity } & $<0.001$ \\
\hline $6 / 15-6 / 60$ & 6 & 2 & 3 & 11 & $0.049^{* *}$ \\
\hline NLP & 0 & 0 & 10 & 10 & $<0.001^{*}$ \\
\hline \multicolumn{5}{|l|}{ OTS score } & $<0.001$ \\
\hline $1(0-44)$ & 0 & 0 & 7 & 7 & $<0.001^{*}$ \\
\hline $2(45-65)$ & 4 & 2 & 11 & 17 & 0.009 \\
\hline $3(66-80)$ & 18 & 5 & 6 & 29 & $<0.001^{* *}$ \\
\hline \multicolumn{5}{|l|}{ Sympathetic ophthalmia } & 0.297 \\
\hline \multicolumn{5}{|l|}{ Endophthalmitis } & 0.297 \\
\hline
\end{tabular}

*positive correlation; ** negative correlation; BETT — Birmingham eye trauma terminology; OTS — ocular trauma score; no NLP — light perception; RD — retinal detachment. Note: only relevant data is listed

The current study did not find a statistically significant association between visual outcome prognosis and age, gender, and the time lag between injury onset and hospital attendance. However, other studies found that age has an important influence on VA prognosis $[12,13]$. Agrawal et al. [12] found a significant associa- tion between the time lag between the injury onset and hospital admission and the final VA of the patients.

Our results showed that the most frequent place of injury was the playground (59\% of cases) in contrast with previous literature, where most injuries were occupational injuries $[5,8]$. Other 
studies have confirmed that most OGIs occur at home [9] or at work settings, as reported by studies conducted in Turkey [7] and UK [11]. Our study showed that of the 22 work-related injuries (representing $26.5 \%$ of cases), only 2 cases (2.4\%) were by children.

Although car accidents are an important cause of OGI, there were no cases due to automobile accidents in our current study. Referral to general hospitals of major trauma with ocular involvement can explain this situation.

Since eye injuries occur during unsupervised activities of the children, parents, teachers, and caregivers should always be on high alert during children's playtimes. Caregivers should also educate children about the risks of dangerous objects such as sharp tools, stones, or sticks.

Our study showed that the offending objects that caused rupture injuries in $100 \%$ of cases included fist, glass, and kinetic impact projectiles. Damages caused by stones caused rupture injuries in $76.5 \%$ of cases.

Kinetic impact projectile injuries caused by rubber bullets represented $10.8 \%$ of cases with a mean age for patients of 22.7 years.

In our study, the most recorded types of injuries were penetration and rupture. Also, the study confirmed that out of the 33 rupture cases, $60.6 \%$ suffered from profound visual loss. And although out of 38 penetration cases, $39.5 \%$ suffered from profound visual loss, when penetration cases with IOFB (6 cases), $66.7 \%$ suffered from profound visual loss. These findings agree with the previous studies [6]. Although protective glasses are mandated at workplaces, still, many people ignore such precautions. Thus, we need widespread awareness of public programs.

Anatomically, the distribution of open globe injuries showed that most injuries $(65.1 \%)$ occurred in zone I, while $24.1 \%$ occurred in zone II and $(10.8 \%)$ occurred in zone III.

Penetrating injuries often result in severe visual impairment. Direct mechanical damage caused by sharp penetration limited to the anterior segment of the eye results in a favorable visual prognosis. Posterior segment penetrating injuries are associated with an unfavorable prognosis. The mechanical damage to vital structures by such injuries may be so significant that functional vision is instantly destroyed. Most times, however, the application of contemporary vitreoretinal microsurgical techniques to prevent or treat secondary complications results in the preservation of eyes that would otherwise be lost.

Our results also showed that zone III wounds had significantly poorer visual outcomes than those involving zones I or II. Previous studies - which reported a significant association between the posterior extension of the wound and a worse final VA $[5,6,8]$ - support this result.

The OTS assists with predicting the prognosis following ocular trauma [16. OTS scores were assigned between 1 (severe injury and poor prognosis) to 5 (least severe injury and best prognosis). It has a predictive accuracy of approximately $80 \%$. Our study supports that presenting VA was predictive of final VA following treatment and may be a useful indicator of prognosis in emergency acute care settings before ophthalmological evaluation.

Our study showed that a poor VA at the first visit was a significant prognostic factor $(\mathrm{p} \leq 0.001)$. A good initial VA was a strong prognostic factor of a favorable final VA, similar to that reported by other studies [5-7].

The variables found to be significant risk factors for low VA outcome were demonstration activities, street injuries, kinetic impact projectiles, zone III injuries, globe disruption, retinal detachment, vitreous hemorrhage, and a poor VA during the first visit. The literature showed that poor presenting VA and retinal detachment are important risk factors for poor visual outcome8.

Our current study showed that retinal detachment and vitreous hemorrhage were poor prognostic factors for visual outcomes. These findings agree with previous studies $[5,6,10]$.

Eye-removal surgery (enucleation and evisceration) is a last resort procedure and imposes a heavy burden of decision for both the ophthalmologist and the patient. Eight eyes (9.6\%) were removed in our series, and in 7 of those cases, the physician performed the procedure during the primary surgery. The incidence of eye-removal surgery was compatible with some studies [11] but was lower than the $24 \%$ and 26\% in other studies [10].

Endophthalmitis is one of the most dangerous complications of OGI. The reported incidence of endophthalmitis post-OGIs varied between 0 and $16.5 \%$ [3]. Our findings are lower than the literature, where one case $(1.2 \%)$ of endophthalmitis developed.

We witnessed an overall improvement in VA after surgical procedures. We also observed an improvement in VA, which was statistically associated 
with the presence of zone I injury, iris prolapse, and OTS score 3.

It is evident, in this study, that there were no injuries caused by toys or organized sport (compared with $7.9 \%$ for toys [14] and anywhere between $10-20 \%$ for sports [15]).

Our study has several limitations. First, being retrospective in design, and some important characteristics were missing, such as eye protection, relative afferent pupillary defect on admission, length of the wound, and size of foreign bodies. For this reason, we did not include these variables in the statistical analysis. The final VA following treatment was not documented at a specific time following surgery, but it was documented as final VA at the time of discharge in most cases. Another limitation is that not all cases of trauma in Palestine reached St. John's Eye Hospital.

\section{CONCLUSION}

This study showed that the act of demonstration, street injuries, kinetic impact projectiles, zone III injuries, globe disruption, retinal detachment, vitreous hemorrhage, and a poor VA at the first visit are poor prognostic factors for OGI. Recognition of these prognostic factors will help the ophthalmologist estimate the severity of eye injury and its prognosis. It may help patients with more realistic expectations of their final VA.

\section{REFERENCES}

1. Kuhn $F$, Morris R, Witherspoon CD, et al. Birmingham Eye Trauma Terminology (BETT): terminology and classification of mechanical eve injuries. Ophthalmol Clin North Am. 2002; 15(2): 139-43, v, doi: 10.1016/s0896-1549(02)00004-4, indexed in Pubmed: 12229228.

2. Pieramici DJ, Sternberg P, Aaberg TM, et al. A system for classifying mechanical injuries of the eye (globe). The Ocular Trauma Classifica- tion Group. Am J Ophthalmol. 1997; 123(6): 820-831, doi: 10.1016/ s0002-9394(14)71132-8, indexed in Pubmed: 9535627.

3. Négrel $A D$, Thylefors $B$. The global impact of eye injuries. Ophthalmic Epidemiol. 1998; 5(3): 143-169, doi: 10.1076/opep.5.3.143.8364, indexed in Pubmed: 9805347.

4. Banayot R. The profile of eye disease in palestine: An 8-year experience at St. John Eye Hospital, Hebron. Ibnosina J Med Biomed Sci. 2018; 10(4): 130, doi: 10.4103/ijmbs.ijmbs 4718.

5. Madhusudhan ALP, Evelyn-Tai LiM, Zamri N, et al. Open globe injury in Hospital Universiti Sains Malaysia — A 10-year review. Int J Ophthalmol. 2014; 7(3): 486-490, doi: 10.3980/j.issn.2222-3959.2014.03.18, indexed in Pubmed: 24967196.

6. Han SB, Yu HG. Visual outcome after open globe injury and its predictive factors in Korea. J Trauma. 2010; 69(5): E66-E72, doi: 10.1097/ TA.0b013e3181cc8461, indexed in Pubmed: 20404759.

7. Yalcin Tök O, Tok L, Eraslan E, et al. Prognostic factors influencing final visual acuity in open globe injuries. J Trauma. 2011; 71(6): 1794-1800, doi: 10.1097/TA.0b013e31822b46af, indexed in Pubmed: 22182891.

8. Thevi T, Mimiwati Z, Reddy SC. Visual outcome in open globe injuries. Nepal J Ophthalmol. 2012; 4(2): 263-270, doi: 10.3126/nepjoph. v4i2.6542, indexed in Pubmed: 22864032.

9. Falcão M, Camisa E, Falcão-Reis F. Characteristics of open-globe injuries in northwestern Portugal. Ophthalmologica. 2010; 224(6): 389-394, doi: 10.1159/000316689, indexed in Pubmed: 20606493.

10. Schmidt GW, Broman AT, Hindman HB, et al. Vision survival after open globe injury predicted by classification and regression tree analysis. Ophthalmology. 2008; 115(1): 202-209, doi: 10.1016/j. ophtha.2007.04.008, indexed in Pubmed: 17588667.

11. Rahman I, Maino A, Devadason D, et al. Open globe injuries: factors predictive of poor outcome. Eye (Lond). 2006; 20(12): 1336-1341, doi: 10.1038/sj.eye.6702099, indexed in Pubmed: 16179934.

12. Agrawal R, Rao G, Naigaonkar $R$, et al. Prognostic factors for vision outcome after surgical repair of open globe injuries. Indian J Ophthalmol. 2011; 59(6): 465-470, doi: 10.4103/0301-4738.86314, indexed in Pubmed: 22011491.

13. Li $X$, Zarbin MA, Bhagat N. Pediatric open globe injury: A review of the literature. J Emerg Trauma Shock. 2015; 8(4): 216-223, doi: 10.4103/0974-2700.166663, indexed in Pubmed: 26604528.

14. Jandeck C, Kellner U, Bornfeld N, et al. Open globe injuries in children. Graefes Arch Clin Exp Ophthalmol. 2000; 238(5): 420-426, doi: 10.1007/s004170050373, indexed in Pubmed: 10901473.

15. Mishra A, Verma AK. Sports related ocular injuries. Med J Armed Forces India. 2012; 68(3): 260-266, doi: 10.1016/j.mjafi.2011.12.004, indexed in Pubmed: 24532883.

16. Kuhn F, Maisiak R, Mann L, et al. The Ocular Trauma Score (OTS). Ophthalmol Clin North Am. 2002; 15(2): 163-165, doi: 10.1016/ s0896-1549(02)00007-x, indexed in Pubmed: 12229231. 